\title{
Papel da fisioterapia no atendimento a pacientes com Covid-19 em unidades de terapia intensiva
}

A Covid-19 é uma patologia relatada como uma nova pneumonia por coronavírus (2019-nCoV) que pode levar a insuficiência respiratória. As manifestações clínicas incluem febre, tosse seca, dispneia, mialgia, fadiga e evidência radiográfica de pneumonia. Podem ocorrer ainda disfunções orgânicas como choque, síndrome do desconforto respiratório agudo, lesão cardíaca e renal aguda. Estudos sugerem que cerca de 5\% dos pacientes necessitarão de internação em unidades de terapia intensiva (UTI) ${ }^{1}$.

A UTI tem por objetivo, além de preservar a vida humana, fornecer reabilitação especializada no cuidado de pacientes críticos, visando otimizar a qualidade de vida percebida e a reintegração do indivíduo à sociedade. Neste aspecto, é importante o suporte multidisciplinar formado por médicos, fisioterapeutas, enfermeiros, terapeutas ocupacionais, fonoaudiólogos, psicólogos, assistentes sociais, entre outros. Através de um plano terapêutico com metas e objetivos bem definidos, com condutas adequadas ao quadro clínico $^{2}$, a reabilitação funcional idealmente deve se iniciar dentro da terapia intensiva e seguir em um continuum após a alta da UTI, até a recuperação plena do paciente.

A reabilitação precoce, ainda na UTI, favorece um melhor retorno da funcionalidade, menos dias de ventilação mecânica, diminuição do delirium, da fraqueza muscular e dos dias de internação, e melhora na qualidade de vida. Mesmo em um contexto de pacientes mais graves, hipoxêmicos, em uso de ventilação mecânica e/ou oxigenoterapia, a reabilitação física pode ser iniciada na UTI, sempre observando os critérios de estabilidade e segurança, bem como a prescrição individualizada dos exercícios ${ }^{3}$.

Dessa forma, com início precoce, pacientes sedados podem se beneficiar de mobilização, alongamentos passivos e posicionamento funcional para manutenção da integridade muscular e articular. Ao despertar, intubados ou em respiração espontânea, pode-se dar início a exercícios mais ativos, treinos de posturas mais altas, entre outros, a depender do nível de consciência e força muscular, trabalhando dentro da capacidade máxima do paciente. Podem ser usadas técnicas como mentalizar o exercício, realizar movimentos em diagonais funcionais, estimulação elétrica neuromuscular periférica, aparelhos de resistência (pesos, halteres, faixas elásticas), exercícios em decúbito lateral, ponte. As queixas e demandas funcionais relatadas pelo paciente na UTI devem guiar o processo de prescrição e de criação de objetivos e metas individualizadas.

Porém, a capacidade de retorno às atividades pode ser impactada pela dispneia e falta de condicionamento físico, levando a baixa tolerância a atividades. Programas de reabilitação cardiopulmonar podem ser adaptados para pacientes críticos e os exercícios iniciados com uso de ciclos ergômetros, por exemplo, com tempo, intensidade e frequência definidos individualmente (guiados por escalas de esforço percebido, como a escala de Borg). Técnicas de conservação de energia podem ser ensinadas e orientadas aos pacientes para atividades de rotina.

A Covid-19 traz algumas especificidades para a reabilitação do paciente. Devido ao quadro de hipoxemia, a reabilitação deve ser realizada com monitorização e possibilidade de aporte de oxigenoterapia e outras terapêuticas, caso seja necessário. Os materiais terapêuticos devem ser rigorosamente higienizados e, preferencialmente, de uso individual. $\mathrm{O}$ isolamento hospitalar e social, com a ausência do momento de visita e do contato com o meio externo, pode contribuir para baixa aderência terapêutica. Entender as preferências do paciente, a atividade laboral prévia e desejos para o futuro, bem como inserir a família através de contato telefônico ou por videochamadas, pode ajudar na aderência ao processo e suprir essas faltas.

Portanto, as terapias para aumentar a sobrevivência desses pacientes são imprescindíveis; porém, não menos importante é a recondução deles à sociedade da maneira mais funcional possível. Essa questão torna-se importante para o retorno à 
sua participação social e familiar, bem como para a questão econômica; caso contrário, os impactos tanto no nível individual (não retorno às atividades laborais) quanto no coletivo (aumento dos custos com saúde) podem ser drásticos. Desse modo, o processo de reabilitação, papel fundamental do fisioterapeuta, não deve ser esquecido ou minimizado mesmo em um momento de pandemia. A reabilitação precoce pode evitar ou minimizar os déficits, fazendo com que o indivíduo receba alta em plena condição física ou com uma demanda menor por acompanhamento fisioterapêutico pós-alta hospitalar.

$$
\begin{array}{r}
\text { Debora Stripari Schujmann } \\
\text { Universidade de São Paulo (USP) - } \\
\text { São Paulo (SP), Brasil. } \\
\text { bttps://orcid.org/0000-0002-0472-8977 } \\
\text { Raquel Annoni } \\
\text { Universidade Federal do Triângulo Mineiro } \\
\text { (UFTM) - Uberaba (MG), Brasil. } \\
\text { bttps://orcid.org/0000-0003-2416-7465 }
\end{array}
$$

\section{REFERÊNCIAS}

1. Wu Z, McGoogan JM. Characteristics of and important lessons from the coronavirus disease 2019 (Covid-19) outbreak in China: summary of a report of 72314 cases from the Chinese Center for Disease Control and Prevention. JAMA. 2020;323(13):1239-42. doi: 10.1001/jama.2020.2648

2. Cameron S, Ball I, Cepinskas G, Choong K, Doherty TJ, Ellis CG, et al. Early mobilization in the critical care unit: a review of adult and pediatric literature. J Crit Care. 2015;30(4):664-72. doi: 10.1016/j.jcrc.2015.03.032

3. Hodgson CL, Stiller K, Needham DL, Tipping CJ, Harrold M, Baldwin CE, et al. Expert consensus and recommendations on safety criteria for active mobilization of mechanically ventilated critically ill adults. Crit Care. 2014;18:658. doi: 10.1186/s13054-014-0658-y 